\title{
Review: evidence on surgical interventions for distal radial fractures is inconclusive
}

\author{
Handoll HH, Madhok R. Surgical interventions for treating distal radial fractures in adults. Cochrane Database Syst Rev \\ 2001(4):CD003209 (latest version 29 Mar 2001).

\section{QUESTION: In adults with fractures of the distal radius, is surgical treatment effective for improving clinical outcome?}

\section{Data sources}

Studies were identified by searching 6 databases: the National Research Register Issues, the Cochrane Musculoskeletal Injuries Group's specialised register, the Cochrane Controlled Trials Register, Medline, EMBASE/Excerpta Medica, and CINAHL; hand searching conference proceedings; and scanning reference lists.

Source of funding: East Riding and Hull Health Authority, UK.

For correspondence: Professor R Madhok, University of Hull, Willerby, UK.

rajan.madhok@

eriding-ha.northy.nhs.uk.

\section{Study selection}

Randomised or quasi-randomised controlled trials were selected if they compared surgical interventions with conservative interventions or other surgical interventions in adults with fracture of the distal radius.
Surgical interventions for fracture of the distal radius*

\begin{tabular}{|c|c|c|c|c|}
\hline Outcomes & Comparisons & $\begin{array}{l}\text { Weighted } \\
\text { event rates }\end{array}$ & RRR $(95 \%$ CI) & NNT (CI) \\
\hline \multirow{6}{*}{$\begin{array}{l}\text { Functional grading }(\mathrm{FG}) \\
\text { not excellent }\end{array}$} & Ext fix $v$ PC & $55 \%$ v $67 \%$ & $18 \%$ (4 to 31 ) & 9 (5 to 36$)$ \\
\hline & PTF $v$ PC & $43 \%$ v $81 \%$ & $47 \%$ (29 to 61 ) & 3 (2 to 5$)$ \\
\hline & Bone scaf $v$ PC & $54 \% \vee 78 \%$ & $31 \%$ (13 to 45$)$ & 5 (3 to 10$)$ \\
\hline & & & RRI (Cl) & NNH (Cl) \\
\hline & PSF $v$ PC & $100 \%$ v 84\%† & $19 \%(5.7$ to 39$)$ & 7 (4 to 13$)$ \\
\hline & & & RRR (Cl) & NNT (Cl) \\
\hline FG fair or poor & PTF $v$ PC & $12 \%$ v $37 \%$ & $69 \%$ (36 to 85 ) & 4 (3 to 9 ) \\
\hline \multirow{3}{*}{$\begin{array}{l}\text { Redisplacement } \\
\text { needing secondary } \\
\text { treatment }\end{array}$} & Ext fix $v$ PC & $0.9 \%$ v $22 \%$ & $89 \%$ (76 to 95$)$ & 5 (4 to 7 ) \\
\hline & PF $v$ PC & $0 \%$ v $20 \%$ & $92 \%$ (63 to 98 ) & 6 (4 to 8 ) \\
\hline & & & RRI (CI) & NNH (Cl) \\
\hline Pin track infection & Ext fix $v$ PC & $11 \%$ v $0 \%$ & $\begin{array}{l}648 \% \text { (149 to } \\
2148 \text { ) }\end{array}$ & 10 (7 to 16$)$ \\
\hline
\end{tabular}

${ }^{*}$ Bone scaf = bone scaffolding; Ext fix = external fixation; $\mathrm{PC}=$ plaster cast; $\mathrm{PF}=$ percutaneous fixation; $\mathrm{PSF}=$ pins supporting fracture; $\mathrm{PTF}=$ pins through fracture. Other abbreviations defined in glossary; RRR, RRI, NNT, NNH, and Cl calculated from data in article using a random effects model. +Event rates not weighted.

\section{Data extraction}

Data were extracted on patient characteristics, intervention, and outcomes (including functional and anatomic outcomes and complications). The quality of studies was assessed.

\section{Main results}

44 studies (3193 mainly female and older patients with 3197 fractures) with 23 different comparisons met the selection criteria, with 6 weeks to 10 years of follow up. Summarising the outcomes was impeded by the poor quality and variation in study methods, interventions, patient characteristics, and outcomes. Some anatomical and functional outcomes (table) were better in the external-fixation group (7 studies), the pins-throughfracture group (4 studies), and the bone-scaffolding group ( 2 studies) than in the plaster-cast group; differences in function for open reduction and internal fixation or bone graft or substitute relative to plaster cast are not reported here because studies had excessive losses to follow up or results were no longer significant when the random effects model was used. External fixation and percutaneous pinning led to fewer patients with redisplacement that required secondary treatment than did a plaster cast; external fixation led to more patients with pin-track infection than did a plaster cast (table). The evidence did not show clear superiority for 1 surgical intervention over another.

\section{Conclusions}

In patients with distal radial fractures, heterogeneity exists for patients, mechanism of fracture, and fracture type, and results are inconsistent. Some benefit in reduced deformity, reduced malunion, and better functional outcome is seen for external fixation and percutaneous pinning relative to plaster cast, but who will benefit sufficiently is unclear.

\section{COMMENTARY}

Debate exists about the degree to which normal anatomy needs to be restored after distal radial fracture. Most clinicians agree that the articular surface should be made congruous, that shortening should be minimised, and that palmer tilt should be restored to at least neutral. ${ }^{1}$ The methods to achieve and maintain reduction can be grouped into casting and percutaneous or open techniques, although many variations of each exist.

Most clinicians consider high energy multifragmentary distal radial fractures with intra-articular displacement as distinct from low energy fractures with a congruous joint when choosing appropriate treatment. However, many of the studies in the review by Handoll and Madhok have inappropriately evaluated all injuries together. The myriad of treatment variations described, the wide range of outcomes evaluated, and the lack of injury discrimination have made it difficult to draw firm conclusions from the literature. Casting is associated with the highest probability of a poor anatomic result, especially in high energy injuries and those with metaphyseal comminution. Alternative treatment to casting should be considered when an acceptable reduction cannot be achieved or when residual joint incongruity and metaphyseal redisplacement is likely especially in high energy injuries. It seems reasonable to approach these high energy injuries with minimally invasive techniques and to resort to open reduction if anatomic restoration is not possible. The role of arthroscopy and adjunctive bone grafting or substitution to obtain and maintain reduction has yet to be elucidated. ${ }^{2}$

Large prospective trials with appropriate injury discrimination and consistent outcome evaluation are needed before firm recommendations can be made about the degree of anatomic restoration required, and the best treatment to use in a particular situation. Existing practices are based largely on expert opinion.

Hans J Kreder, MD, MPH University of Toronto, Toronto, Ontario, Canada

1 Hanel DP, Jones MD, Trumble TE. Wrist fractures. Orthop Clin North Am 2002;33:35-57.

2 Trumble TE, Culp RW, Hanel DP, et al. Intra-articular fractures of the distal aspect of the radius. Instr Course Lect 1999;48:465-80. 